\title{
Protocol Development Shared Resource
}

National Cancer Institute

\section{Source}

National Cancer Institute. Protocol Development Shared Resource. NCI Thesaurus. Code C39499.

The Protocol Development Shared Resource provides Cancer Center investigators with support in clinical and experimental research protocol development, including protocol content and form, sample size and patient safety related issues, and cost estimates to aid in budget development. 